
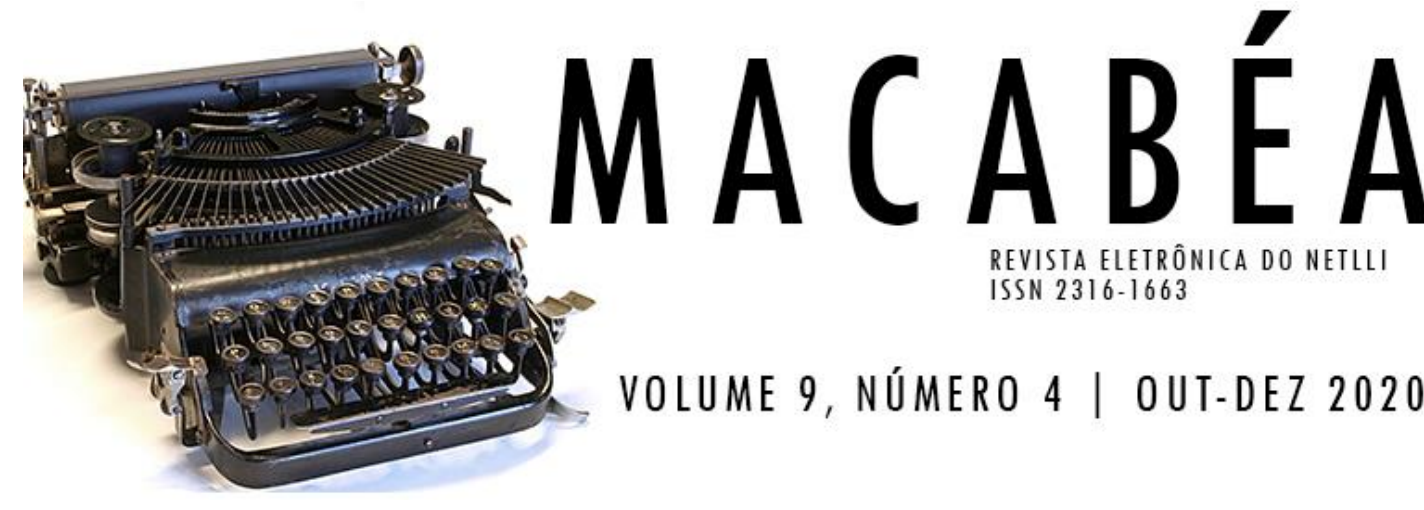

REVISTA ELETRÔNICA DO NETLLI ISSN 2316-1663

\title{
A PESTE, DE ALBERT CAMUS: UMA LEITURA SOB A ÓTICA DA METAFICÇÃO HISTORIOGRÁFICA
}

\section{THE PLAGUE, BY ALBERT CAMUS: A READING FROM THE PERSPECTIVE OF HISTORIOGRAPHICAL METAFICTION}

\author{
KEILIANE DA SILVA ARAÚJO CARVALHO \\ UNIVERSIDADE ESTADUAL DO PIAUÍ, BRASIL \\ MARIA SUELY DE OLIVEIRA LOPES \\ UNIVERSIDADE ESTADUAL DO PIAUÍ, BRASIL
}

\author{
RESUMO | INDEXAÇÃO | TEXTO | REFERÊNCIAS | CITAR ESTE ARTIGO | AS AUTORAS \\ RECEBIDO EM 11/07/2020 • APROVADO EM 12/09/2020
}

\begin{abstract}
Released in 1947, The Plague, by Albert Camus, focuses on the change that the life of the citizens of Oran goes through. The trivial aspect of the city is commuted abruptly with the emerging of the plague which, transmitted through a multitude of rats, annihilates the population. Beyond the representation of the epidemic and as Shoshana Felman points out (2000), the narrative is an allegory of the massive deaths caused by World War II. The author explains, in addition, that the novel portrays the Europeans' trauma, who, put into "quarantine" by German occupation, fought against the genocide undertaken by the Nazi oppression. The Plague (1947) is presented to us by the doctor Bernard Rieux. He acts as a historian as he gathers a series of statements. An amateur, indeed, but armed with several documents and inclined to reconstitute the history of the flagellum he lived. Thus, the narrator's pluriangular exposition allows another understanding of the
\end{abstract}


historical dimension that surrounds the aforementioned catastrophe. This said, this work's goal is to evidence that the narrative can be read from the perspective of historiographical metafiction, since it uses explicative means over its construction and portrays a historical moment. As it's known, in postmodernity, the historiographical metafictional discourses provide an epistemological transformation because they provide a heterogeneous disclosure: the winners' one and the losers' one. During a long time, the official history deified the former and relegated the latter, by marginalizing them and/or limiting them to silence and even to total oblivion. In this regard, these narratives, while executing a social role, have a revisionist content. The analysis is supported by the ideas of Linda Hutcheon (1991); Shoshana Felman (2000); José Carlos Reis (2000); François Hartog (2013), etc.

\section{Resumo}

Lançada em 1947, $\boldsymbol{A}$ Peste, de Albert Camus, focaliza a mudança que perpassa a vida dos concidadãos de Oran. 0 aspecto banal da cidade é comutado de maneira abrupta com 0 surgimento da peste que, transmitida por uma infinidade de ratos, vai aniquilando a população. Para além da representação da epidemia e conforme aponta Shoshana Felman (2000), a narrativa é uma alegoria da morte em massa ocasionada pela Segunda Guerra Mundial. A autora explica, ainda, que o romance dá vasão ao trauma dos europeus que, postos em "quarentena" pela ocupação alemã, lutavam contra 0 genocídio empreendido pela opressão nazista. A Peste (1947) nos é apresentada pelo médico Bernard Rieux. Este, ao reunir uma série de depoimentos, age como um historiador. Amador, a bem da verdade, mas munido de documentos vários e disposto a reconstituir a história do flagelo que vivenciara. Assim, a exposição do narrador, que é pluriangular, permite uma outra compreensão da dimensão histórica que circunda a catástrofe supracitada. Dito isso, 0 objetivo deste trabalho é o de evidenciar que a narrativa pode ser lida sob 0 viés da metafiç̧ão historiográfica, porque dispões de artifícios explicativos sobre a sua construção e retrata um momento histórico. Como se sabe, os discursos metaficcionais historiográficos, na pós-modernidade, proporcionam uma transformação epistemológica, porque permitem uma evidenciação heterogênea: dos vencedores e dos vencidos. A história oficial, durante muito tempo, deificou aqueles e relegou estes, marginalizando-os e/ou limitando-0s ao silenciamento e, até mesmo, ao apagamento total. Nesse sentido, essas narrativas, cumprindo um papel social, dispõem de um teor revisionista. A análise está apoiada nas ideias de Linda Hutcheon (1991); Shoshana Felman (2000); José Carlos Reis (2000); François Hartog (2013), etc.

\section{Entradas para indexação}

KEYWORDS: Metafiction. History. Literature. The Plague. Albert Camus.

PALAVRAS-CHAVE: Metaficção. História. Literatura. A peste. Albert Camus.

\section{Texto integral}

\section{HISTÓRIA E LITERATURA: UM DIÁLOGO AMISTOSO}

$\mathrm{Na}$ atualidade, os debates formulados a respeito do tríplice enlace história, literatura e ficção são amplamente difundidos. Muitos são os teóricos que versam sobre essas temáticas - Hayden Whaite, Luiz Costa Lima, José Carlos Reis, entre outros - e múltiplas são as diferenciações e similitudes circunscritas a cada área. No entanto, não objetivamos traçar um panorama do que cabe nesses campos, uma vez 
que a discussão se estenderia de maneira demasiada. Partiremos, portanto, de uma problematização comum ao discurso histórico, a de que ele não produz um "conhecimento objetivo", para, assim, apontarmos a sua confluência com o discurso literário.

A história, enquanto registro empreendido pelos historiadores, pautavase numa "legitimidade" discursiva no que toca o passado, tendo em vista a ideia de que o "conhecimento histórico encontraria sua validade na operação concreta de historiadores concretos e não em uma definição ideal e apriorística, atemporal, do que deveria ser" (REIS, 2000, p. 323). Fato dado, o que há, atualmente, é uma extensa problematização da dialética História e verdade, - como escreveu José Carlos Reis, no estudo intitulado História e verdade: posições (2000). Dentre os questionamentos mais triviais e como anunciado no início desta seção, o de que a história não produz um conhecimento objetivo (Reis, 2000) merece destaque. Citando K. Popper, Carlos Reis nos ajuda a entender melhor o que cabe nesse conceito:

\begin{abstract}
"Objetivo", nos dicionários, é o que existe fora e independentemente do sujeito. Para Popper, "objetivo" seria um conhecimento independente do capricho pessoal, e justificado, submetido à prova e compreendido por todos. [...] Seria um conhecimento que põe em ordem, compreende e faz compreender. Seria sobretudo um conhecimento estável, pois submetido a regras conhecidas por todos um paradigma. 0 conhecimento objetivo seria aquele que é válido para todos, que é isento de afetividade e parcialidade, que é válido de modo necessário, universal e atemporal; ele apresentaria dados, números, medidas; seria sem valores, paixões, sem tendência, sem desvios e digressões, sem emoções. Um conhecimento objetivo seria analítico, exterior ao sujeito, lógico, submetido a regras, intersubjetivo, válido de modo necessário e universal; produziria juízos de fato e analisaria, constataria, descreveria, demonstraria, calcularia, mediria dados empíricos (REIS, 2000, p. 326).
\end{abstract}

A partir do que Reis tenciona e na esteira do que teorizou Popper, é possível constatar que "a história não produz um 'conhecimento objetivo' [...], o conhecimento é marcado pela emoção, pela intuição, envolve convicções, juízo de valor, tendências, interesses. Não possui um valor cognitivo estável, necessário e universal" (REIS, 2000, p. 326 -327). Essas asserções acabam que por provocar uma reflexão acerca da natureza epistemológica da história, que, mesmo dispondo de paradigmas críveis no que toca a "representação" da realidade, pode abrir brechas para aproximações com o discurso literário, o que nos faz entender que o diálogo entre a história e a literatura não é incongruente, mas, sim, amistoso, profícuo.

Para Afrânio Coutinho (1978, p. 9), a literatura configura-se como uma "transfiguração do real, é a realidade recriada através do espírito do artista e 
retransmitida através da língua para as formas, que são os gêneros, e com os quais ela toma corpo e nova realidade". 0 autor explica, ainda, que ela, a literatura:

Passa, então, a viver outra vida, autônoma, independente do autor e da experiência de realidade de onde proveio. Os fatos que lhe deram às vezes origem perderam a realidade primitiva e adquiriram outra, graças a imaginação do artista. São agora fatos de outra natureza, diferentes dos fatos naturais objetivados pela ciência ou pela história ou pelo social (COUTINHO, 1978, p. 9-10).

Se, como defende Coutinho, o discurso formulado pela via da literatura transmuta os fatos em razão de um eu que os escreve, que os imagina, que materializa o discurso, a história, como sugeriu Carlos Reis, acima, também, não foge disso. É nesse sentido que o discurso veiculado pela literatura aproxima-se do historiográfico. Dadas as devidas proporções, tanto a história como a literatura são como "modalidades de um exercício imaginário de reconstrução do mundo" (PASSAVENTO, 2003, p. 32). Dessa maneira, " tanto o historiador quanto o romancista são responsáveis pela construção ou revisão da realidade social culturalmente constituída pela sociedade que de certa forma representa ou na qual está completamente inserida" (SILVA, 2007, p. 32), cada qual a seu modo, pelo viés de suas próprias narrativas e de seus próprios conjuntos idiossincráticos.

Em razão disso, é oportuno refletir, assim como Luiz Costa Lima (1989) o fez, que a narrativa não pode ter seu tratamento limitado aos campos da história e da ficção. Isso porque, tal feito, explica o mesmo autor:

Terminaria por respeitar a velha distinção entre ciências nomotéticas e idiográficas. [...], sem se negar a importância do exame mais acurado das proximidades e diferenças dos discursos historiográfico e ficcional, encerrá- lo aí daria· a entender que aí estaria o próprio limite da narrativa; que o oposto dela seria o nomos, a lei, que abrangeria todo o território das ciências exatas (LIMA, 1989, p. 16 - itálico do autor.)

Nesse sentido e conforme o juízo formulado no trecho destacado, estabelecer um limite eminentemente ontológico entre os dois tipos de narrativas seria limitá-las e reduzi-las a uma perspectiva dissidente. Com efeito, ambos os discursos não podem ter uma "relação opositiva como critério orientador" (LIMA, 2002, p. 957). Assim, importa destacar que a ficção e a história são narrativas próximas, diferenciadas apenas por um arquétipo particularizador que as definem como tal, como afirma Linda Hutcheon (1991). 
Para Hutcheon (1991, p. 122), ainda, "o que a escrita pós-moderna da história e da literatura nos ensinou é que a ficção e a história são discursos, que ambas constituem sistemas de significação pelos quais damos sentido ao passado". A autora esclarece, também, que as duas áreas:

Obtêm suas forças a partir da verossimilhança, mais do que qualquer verdade objetiva: as duas são identificadas como construto linguísticos, altamente convencionalizadas em suas formas narrativas, e nada transparentes em termos de linguagem ou estrutura; e parecem ser igualmente intertextuais, desenvolvendo os textos do passado com a sua própria textualidade complexa (HUTCHEON, 1991, p. 141).

À medida que Hutcheon (1991) avulta a confluência entre o discurso histórico e o literário, chama a atenção para os ensinamentos implícitos de metafcção historiográfica, que, também, se constitui a partir dessas mesmas especificidades supracitadas, como será demonstrado na subdivisão que sucede este tópico.

Partindo dessas acepções, o objetivo deste estudo é o de evidenciar que o romance A Peste (1947), de Albert Camus, pode ser analisado sob o viés metaficcional historiográfico, porque dispõe de um caráter revisionista e apresenta explicações que situam o leitor no seu processo artístico-construtivo. Essa leitura será possível, ainda, por que a narrativa, conforme afirma Shoshana Felman (2000, p. 22), configura-se como uma "alegoria transparente da morte em massa causada pela Segunda Guerra Mundial e do trauma dos europeus postos em 'quarentena' pela ocupação alemã e lutando [...] contra a mortandade opressora do Nazismo".

Assim, faremos um estudo crítico do objeto em questão, a partir de construtos teóricos que versam sobre as temáticas da metaficção e metaficção historiográfica, de modo a apontar alguns de seus elementos constitutivos "natureza ficcional", caráter revisionista - na análise a seguir.

\section{METAFICÇÃO E METAFICÇÃO HISTORIOGRÁFICA: CONSIDERAÇõES TEÓRICAS}

Ao desenvolver estudos concernentes à metaficção ${ }^{1}$, Hutcheon (1991) formula explicações substanciais que nos ajudam a entender melhor o conceito. Segundo ela, a metaficção trata-se de uma "ficção que inclui em si mesma um comentário acerca de sua natureza ficcional e/ou identidade linguística"

\footnotetext{
${ }^{1}$ Em conformidade com o que sugere Gustavo Bernardo (2010), William Gass criou o termo "metafiction para designar os novos romances americanos do século XX. Tais romances subvertem os elementos narrativos canônicos para estabelecer um diálogo entre ficções" (p. 39), em 1958, o que resultou em uma vasta contribuição para o estudo de romances que destoavam de um aspecto mais ortodoxo.
} 
(HUTCHEON, 1991, p. 1). Necessário ao entendimento do termo é, ainda, o juízo formulado por Gustavo Bernardo (2010, p. 42), que contribui para a discussão ao afirmar que a "metaficção é uma ficção que não esconde o que é, mantendo o leitor consciente de estar lendo um relato ficcional, e não um relato da própria verdade". Dessa maneira, o literato, consciente, lança mão de artifícios que proporcionam, ao leitor, um conhecimento sobre o processo de criação que ele empreende. Isso porque a metaficção é caracterizada como "um fenômeno estético autorreferente e através do qual a ficção duplica-se por dentro, falando de si mesma ou contendo si mesma" (BERNARD0, 2010, p. 9), e, sendo assim, é "narcisista", no sentido proposto por Hutcheon (1984).

Paralelo a isso, clarificamos que a metaficção e a metaficção historiográfica se constituem por especificidades que as colocam em posições antitéticas. No intento de diferenciá-las, esclarecemos que o conceito desta última tem como característica básica a apropriação de personagens, bem como de acontecimentos históricos, enfocados à luz de uma perspectiva problematizadora do que é posto como genuíno, conforme teorizou Hutcheon (1991). A autora explica, posteriormente, que as metaficções historiográficas "privilegiam duas formas de narração, que problematizam toda a noção de subjetividade: os múltiplos pontos de vista [...]" (HUTCHEON, 1991, p. 156). Nesse sentido, a metaficção historiográfica difere de um romance histórico ${ }^{2}$, por exemplo, porque pauta-se não na evidenciação dos fatos, mas os enfoca a partir de um caráter auto-reflexivo, possibilitando questionamentos acerca das "verdades" históricas pré-estabelecidas.

Para além disso, dotada de uma perspectiva eminentemente pósmodernista, “[...] a metaficção historiográfica procura desmarginalizar o literário por meio do confronto com o histórico, e o faz tanto em termos temáticos como formais" (HUTCHEON, 1991, p. 145). Dessa maneira, a autora provoca uma reflexão acerca das vantagens de que dispõem o texto literário, uma vez que o discurso histórico, ao contrário da literatura, possui uma "forma de escrever limitada à representação do contingente e do particular" (1991, p. 145).

Outrossim, vale mencionar, ainda, que o passado, nas narrativas pósmodernistas, é enfatizado mediante epistemologias do contexto atual. Em razão disso, elas (as narrativas), proporcionam uma releitura crítica do passado, resinificando-o e proporcionando, aos leitores, novas formas de significação. A fim de melhor explicitar, as palavras da autora se fazem necessárias, pois sugerem que:

Com esse termo [metaficção historiográfica], refiro-me àqueles romances famosos e populares que, ao mesmo tempo, são intensamente auto-reflexivos e mesmo assim, de maneira paradoxal, também se apropriam de acontecimentos e personagens históricos [...] (HUTCHEON, 1991, p. 21).

\footnotetext{
${ }^{2}$ Em conformidade com o que sugere Lukács (1971), o romance histórico, tendo como contexto histórico a Revolução Francesa, surgiu em meados do século XIX, sendo seu precursor Walter Scott. Para ele, ainda. - O romance histórico de Scott é uma continuação em linha reta do grande romance social realista do século XVIIIII (LUKÁCS, 1971, p. 30).
} 
De acordo com Hutcheon (1991), ainda, a metaficção historiográfica procura (re) apresentar o passado, de maneira que essa (re) apresentação não se reduza a uma mera representação pela via da ficcionalização dos fatos e de personagens históricos. Conforme sugere a mesma autora, esse processo se dá de maneira paródica, irônica e, até mesmo, de forma satírica.

Somando, Bernardo (2010, p. 42) contribui ao evidenciar que a intertextualidade por meio da paródia, do pastiche, do eco, da alusão, da citação direta e, também, do paralelismo estrutural encorpam essas novas narrativas metafciocionais (aspectos que não serão contemplados no decorrer da análise). Tais estratégias discursivas proporcionam a conscientização do leitor no que toca o seu entremeio, a sua realidade, uma vez que a narrativa histórica de ficção opera de maneira crítica, e traz à luz os problemas ocultados pela história oficial (Hutcheon, 1991).

\section{A PESTE, DE ALBERT CAMUS: UMA LEITURA SOB A ÓTICA DA METAFICÇÃO HISTORIOGRÁFICA}

Nascido na Argélia, em 1913, Albert Camus, autor de O Estrangeiro (1942), 0 Mito de Sísifo (1942) e A Peste - dentre outras produções -, é um dos grandes nomes da literatura e da filosofia francesa. Suas obras são marcadas por temáticas concernentes às experiências humanas, perspectivadas sob um prisma multifacetado e existencialista, o que é possível perceber no objeto de análise deste estudo, ainda que este não seja o foco.

Para além disso, A Peste (1947) dispõe de um caráter metaficcional, uma vez que é composta por artifícios explicativos sobre o seu próprio processo de construção. Contemplando esse aspecto, o objetivo desta análise, repetimos, é evidenciar que a narrativa camusiana pode ser lida sob o viés metafcional historiográfico, porque, além da idiossincrasia supracitada, também, retrata e problematiza um momento histórico: a opressão do regime nazista, ainda que sem verbalizá-la, ainda que de maneira eminentemente alegórica. Gradativamente, os leitores do romance vão sendo conduzidos a comensurar a violência ocorrida em Oran. Assim, os testemunhos circunscritos à invasão, à censura, ao toque de recolher, ao exílio e, mais extremadamente, às milhares de mortes, etc., conferem crivo à assertiva de que a obra é uma representação da ocupação alemã.

Lançado em 1947, o romance focaliza a mudança que perpassa a vida dos concidadãos da cidade argelina. A aparência banal de Oran é comutada de maneira abrupta com o surgimento da peste que, transmitida por uma infinidade de ratos e por uma patologia epidêmica, vai aniquilando a população. Se, como já evidenciado, acima, A Peste (1947) dá vazão aos desmandos empreendidos pela opressão nazista, em caráter alegorizante, Camus, pela voz do narrador-personagem, dá pistas de que a narrativa deve ser lida como tal, ao clarificar que a palavra peste não significa apenas o "que a ciência queria definitivamente atribuir-lhe, mas uma longa 
série de imagens extraordinárias que não combinavam com essa cidade amarela e cinzenta" (CAMUS, 1947, p. 32), imagens estas que simbolizam o horror.

Com as primeiras aparições de ratos mortos e gânglios a estourar nos corpos dos concidadãos, a população de Oran se vira intrigada. Após a instalação do medo e reflexões diversas: o entendimento. E, assim:

A palavra "peste" acabava de ser pronunciada pela primeira vez. Neste momento da narrativa, com Bernard Rieux atrás da janela, permitir-se-á ao narrador que justifique a incerteza e o espanto do médico, já que, com algumas variações, sua reação foi a da maior parte dos nossos concidadãos. Os flagelos, na verdade, são uma coisa comum, mas é difícil de acreditar quando se abatem sobre nós. Houve no mundo tantas pestes e guerras. E contudo, tanto as pestes, como as guerras, encontram sempre as pessoas igualmente desprevenidas (CAMUS, 1947, p. 30).

A invasão repentina do regime totalitário em Oran demonstra a "arbitrariedade com que as vítimas podem ser escolhidas, e para isso é decisivo que sejam objetivamente inocentes, que sejam selecionadas sem que se atente para o que possam ou não ter feito" (ARENDT, 2012, p. 30). Na cidade argelina, o flagelo foi igualmente aniquilador para homens, mulheres e crianças, porque "o terror, há meses, não escolhia" (CAMUS, 1947, p. 148) a quem vitimar.

Para F. Hartog (2013), A Peste (1947) apresenta-se como um "testemunho, uma 'Crônica'”. “'Tendo sido convocado a testemunhar por ocasião de um tipo de crime', começa por declarar o narrador, o Dr. Rieux; em seguida, acrescenta que ele 'manteve certa reserva', como convém a uma testemunha de boa vontade, mesmo que ele se posicione do lado das vítimas. [...]" (HARTOG, 2013, p. 210). Como descrito, o romance nos é apresentado pelo Dr. Bernard Rieux. Este, ao reunir uma série de depoimentos, seus e dos que lutaram contra a violência da ocupação, age como um historiador. Amador, a bem da verdade, mas munido de documentos vários e disposto a reconstituir a história do flagelo que vivenciara. Assim, a exposição do médico, porque um exercício retórico, atinge uma postura pluriangular, uma vez que evidencia diferentes pontos de vista e permite uma outra compreensão da dimensão histórica que circunda a catástrofe supracitada. Tal especificidade apresenta um caráter problematizador da história oficial, o que, dentre outros aspectos, nos faz examinar a narrativa sob o prisma metaficcional historiográfico.

Partindo da concepção de que a peste, a epidemia, configura-se como um sucedido catastrófico, vale pensar, como S. Zizek (2017, p. 12) o fez, que um acontecimento (uma catástrofe) se caracteriza "pelo surgimento surpreendente de algo novo solapa qualquer esquema estável [...] um trauma que desestabiliza a ordem simbólica em que existimos". É assim, pois, que: 
Oran deixa de ser uma cidade pacata, dando lugar aos primeiros sinais dos acontecimentos graves cuja crônica nos propusemos fazer aqui. Esses fatos parecerão a alguns perfeitamente naturais e a outros, pelo contrário, inverossímeis. Mas, afinal, um cronista não pode levar em conta essas contradições. Sua tarefa é apenas dizer: -Isso aconteceu\|, quando sabe que isso, na verdade, aconteceu; que isso interessou à vida de todo um povo, e que, portanto, há milhares de testemunhas que irão avaliar nos seus corações a verdade do que ele conta (CAMUS, 1947, p. 9).

Dessa maneira, a cidade de Oran, ocupada pelo flagelo, é afetada por uma série de episódios que "interrompem processos e procedimentos de rotina" (ARENDT, 1985, p. 5) dos concidadãos. Além disso, os testemunhos de personagens como Cottard; Rambert; Tarrou e Grand, dentre outros, dão materialidade à crônica escrita por Rieux. Tal empreitada baseia-se numa tentativa não de formular "verdades", de modo a impô-las, mas em proporcionar, aos receptores de sua narrativa, uma capacidade de dimensionar o que ele pretende anunciar. 0 objetivo de Rieux não é o de construir um absolutismo, porque o seu próprio fazer artístico tenciona a desconstrução de verdades ontológicas contadas por quem detém o poder.

No romance, Dr. Rieux assume papéis distintos: historiador, ficcionista e testemunha. Conforme Felman (2000), os fatos históricos existentes na narrativa camusiana "falham em dar totalmente conta da natureza do testemunho, já que aquele que porta o testemunho não é simplesmente um 'historiador', mas, em primeiro lugar, um médico, e já que a história aparece e é registrada por meio da impressionante metáfora de uma doença, a peste" (2000, p. 22 - itálico da autora). A bem da verdade, "ser testemunha nunca foi uma condição suficiente, nem sequer uma condição necessária, para ser historiador" (HARTOG, 2013, p. 203), mas, no entanto, a condição de testemunha é demasiado útil ao processo evolutivo que resulta na crônica que o Dr. Rieux materializa.

Com efeito, no recorte em que diz: "esses fatos parecerão a alguns perfeitamente naturais e a outros, pelo contrário, inverossímeis" (CAMUS, 1947, p. 9), como é possível constatar, Rieux provoca uma reflexão sobre o fazer artístico. Porque confeccionada sob uma perspectiva pós-modernista, a ideia da metaficção historiográfica emerge em meio a paradoxos complexos, como escreveu Hutcheon (1991). Para a autora, a interação do historiográfico com o metaficcional coloca igualmente em evidência a rejeição das pretensões de representação autêntica e cópia inautêntica e o próprio sentido da originalidade artística é contestado (HUTCHEON, 1991, p. 147). Assim, há, no trecho destacado, uma possibilidade de "dupla conscientização da natureza fictícia e de uma base no real" (HUTCHEON, 1991, p. 143). Dessa maneira, cabe ao leitor refletir sobre os fatos narrados diante de sues olhos. A metaficção historiográfica contrapõe os métodos naturais, e/ou de senso comum, a fim de diferenciar o fato histórico e o discurso ficcional, conforme pensou Hutcheon (1991). A autora problematiza a pretensão à verdade de que a história se vale ou a que está circunscrita, e afirma que tanto a "história como a ficção 
são discursos, construtos humanos, sistemas de significação, e é a partir dessa identidade que as duas obtêm sua principal pretensão à verdade" (HUTCHEON, 1991, p. 127). Nessa perspectiva, repetimos, é necessário considerar o lugar enunciativo em que está situado o narrador-personagem, bem como o cabedal discursivo que molda a narrativa para, só assim, atribuir sentido ao posto e não posto, sem pretensa a uma verdade absoluta.

Ao confluir diferentes discursos narrativos, o narrador-personagem trata dos dilemas humanos vividos pela sociedade argelina da época, pois, a partir de uma perspectiva individual, conglomera, também, o coletivo, como se nota nos excertos destacados abaixo:

É isso que o autoriza a agir como historiador. É claro que um historiador, mesmo que não passe de um amador, tem sempre documentos. 0 narrador desta história tem, portanto, os seus: em primeiro lugar o seu testemunho; em seguida, o dos outros, já que, pelo seu papel, foi levado a recolher as confidências de todas as personagens desta crônica; e, finalmente, os textos que acabaram caindo em suas mãos (CAMUS, 1947, p. 9).

E o narrador está convencido de que pode escrever aqui, em nome de todos, o que ele próprio sentiu então, já que o sentiu ao mesmo tempo que muitos dos nossos concidadãos. Sim, era realmente o sentimento de exílio esse vazio que trazíamos constantemente em nós, essa emoção precisa, o desejo irracional de voltar atrás ou, pelo contrário, de acelerar a marcha do tempo, essas flechas ardentes da memória [...] sabíamos então que a nossa separação estava destinada a durar e que devíamos tentar entender-nos com o tempo. A partir de então, reintegrávamo-nos, afinal, à nossa condição de prisioneiros, estávamos reduzidos ao nosso passado e, ainda que alguém fosse tentado a viver no futuro, logo renunciava, ao experimentar as feridas que a imaginação finalmente inflige aos que nela confiam (CAMUS, 1917, p. 71).

Os recortes dimensionam um discurso que "sempre se volta para a reflexividade metadiscursiva" (WHITE, 1994, p. 21). Nesse sentido, Camus trata do flagelo de maneira que o não dito exerce fundamental importância para a construção de sentido que ele almeja alcançar. Em Oran, Dr. Rieux tenciona que "a sociedade dos vivos receava duramente todo o dia ser obrigada a ceder lugar à sociedade dos mortos" (CAMUS, 1947, p. 121), ao emprestar a sua voz ao narrador-personagem, o autor da narrativa se vale de estratégias que cumprem as suas intenções estéticodiscursivas, porque contempla um fato histórico através de uma efígie. Assim, Camus lança mão de mecanismos que ora se "ajustam, ora se excluem, e, entretanto, 
fazem das partes um todo homogêneo pelo entrelaçamento dos dois expedientes empregados no decurso dos cinco capítulos presentes no livro" 3 .

Outro aspecto a ser ressaltado nos fragmentos acima concerne à posição de historiador pretendida por Rieux. No intento de refletir sobre ela, faremos uso das palavras de Hayden White, que, em Meta-história: a imaginação histórica do século $X I X$ (1995), escreve sobre a tenuidade da relação entre o ofício do historiador e do romancista. Para o autor, o pensamento histórico ganha materialidade por meio da representação, e, portanto, não é destituído de ficcionalização. Afinado às ideias de Hutcheon (1991), White explica que o historiador se vale de rastros, "achados" para explicar o passado, e que os achados do historiador são produtos resultantes da pesquisa documental que ele realiza. Para ele, ainda, o ficcionista "inventa" as suas próprias estórias, mas essa invenção também está presente "nas operações do historiador" (WHITE, 1995, p. 22), o que ratifica confluência entre ambos os discursos.

Não obstante, como se sabe, a história oficial é construída sob uma perspectiva que privilegia a posição dos vencedores. No trecho destacado a seguir, Dr. Rieux questiona a consagração do heroísmo de que eles, os gloriosos, dispõem e, também, a vileza creditada, historicamente, aos vencidos:

A grande cidade silenciosa não passava então de um aglomerado de cubos maciços e inertes, entre os quais as efígies taciturnas de benfeitores esquecidos ou de grandes homens antigos, sufocados para sempre no bronze, tentavam sozinhos, com seus falsos rostos de pedra ou de bronze, evocar uma imagem degradada do que fora o homem. Esses ídolos medíocres reinavam sob um céu espesso nas encruzilhadas sem vida, brutos insensíveis que bem representavam o reino imóvel em que havíamos entrado ou pelo menos, a sua ordem última, a de uma necrópole em que a peste, a pedra e a noite teriam feito calar, enfim, todas as vozes (CAMUS, 1947, p. 120).

Em Oran, um amontoado de corpos se liquefazia corriqueiramente. Homens e mulheres eram, continuadamente, jogados em fossas e, "no fundo de cada uma delas, uma espessa camada de cal deixava suas bolhas arrebentarem ao ar livre" (CAMUS, 1947, p. 123), o que dá margem ao entendimento de que o sistema alemão era inequitativo, como afirma Hobsbawm (1995). A Alemanha, explica o mesmo autor, agiu de modo a explorar os "recursos e a mão-de-obra da Europa ocupada, tratou as populações não alemãs como inferiores e, em casos extremos os poloneses, mas sobretudo os russos e judeus, praticamente como mão-de-obra escrava descartável, que não precisava nem ser mantida viva". (HOBSBAWM, 1995, p. 44). 0 horror, na cidade argelina, instalara-se a tal ponto que a morte chegara para todos, inclusive, para crianças, para os inocentes, fato que atesta a arbitrariedade do

3 (OLIVEIRA, 2019, p. 59). Dissertação de mestrado de Ricardo Itaboraí Andrade De Oliveira, intitulada: ACONTECIMENTO, LINGUAGEM E RESISTÊNCIA EM A PESTE, DE ALBERT CAMUS, 2019. 
regime nazista. Por essa ótica, se os discursos oficiais, por vezes, atenuam a barbaridade daqueles que detêm o poder, o romanista, em uma postura denunciativa, delata tais aviltamentos e questiona a abjeção dos vencidos.

Ao falar dos "ídolos medíocres" que reinavam na ocupação, com suas práticas violentas, o narrador-personagem condena a posição de valor alcançada pelos opressores. Ademais, "enquanto a história dos vencedores limita-se a olhar para um só lado, o próprio, a história dos vencidos deve levar em consideração, para compreender o que se passou, os dois lados" (HARTOG, 2013, p. 228). Com efeito, vale destacar a importância de narrativas como A Peste (1947), que pauta-se nessa compreensão bilateral, pois avulta a perspectiva dos vencedores e dos vencidos.

A Peste (1947) é o resultado da experiência mortífera na cidade argelina. No romance, há um narrador consciente do que conta. Ao rememorar e dá materialidade à história do flagelo que acometera Oran, ele dialoga com o leitor e o alerta sobre os horrores que vivenciara:

Mas a noite também estava em todos os corações, e as verdades, como lendas que se contavam sobre os enterros, não eram feitas para tranquilizar nossos concidadãos. Porque é definitivamente necessário falar de enterros, e o narrador pede desculpas (CAMUS, 1947, p. 120).

Como sugere Hutcheon (1991), a metaficção historiográfica, por meio de recursos reflexivos, objetiva informar o leitor sobre seu processo de construção, bem como o de seleção. Para a autora, o recurso da metaficcionalidade tem como pressuposto básico, também, instigar o leitor à co-participação, de modo que ele atue para a construção de sentidos. Paralelo a isso, dentre os aspectos que corroboram a ideia de que o romance é uma alegoria dos desmandos empreendidos pelo regime totalitarista alemão, os relatos das mortes em massa são o que mais a sustenta. Quando a peste regrediu, Rieux se dera conta de que tudo morrera a sua volta:

Do morro escuro, subiram os primeiros foguetes dos festejos oficiais. A cidade saudou-os com uma longa e surda exclamação. Cottard, Tarrou, aqueles e aquela que Rieux tinha amado e perdido, todos mortos ou culpados, estavam esquecidos. 0 velho tinha razão, os homens eram sempre os mesmos (CAMUS, 1947, p. 213).

Durante a instalação do regime em Oran, as perdas foram incalculáveis. Ao escrever sobre o exício ocasionado pela Segunda Guerra Mundial, Hobsbawm (1995, p. 50-51) explica que mesmo as "estimativas aproximadas se mostram impossíveis, pois a guerra matou tão prontamente civis quanto pessoas de 
uniforme, e grande parte da pior matança se deu em regiões, ou momentos, em que não havia ninguém a postos para contar, ou se importar. [...]".

Inconformado, "Dr. Rieux decidiu, então, redigir esta narrativa, que termina aqui, para não ser daqueles que se calam, para depor a favor das vítimas da peste, para deixar ao menos uma lembrança da injustiça e da violência" (CAMUS, 1947, p. 213), para que o manifestado a partir de rememorações, de relatos escritos, não seja esquecido, apagado, silenciado, distorcido.

Por essa ótica, é lúcida a afirmação de que a narrativa, porque articulada por testemunhos de vítimas do flagelo em Oran, que dimensionam o particular e o público, de modo a questionar os acontecimentos despóticos, dispõe de um teor revisionista. Tal feito nos direciona para a reflexão empreendida por Hutcheon (1991, p. 147), que diz que "reescrever ou reapresentar o passado na ficção e na história é - em ambos os casos - revela- lo ao presente, impedi-lo de ser conclusivo e teleológico".

\section{CONSIDERAÇÕES FINAIS}

Conforme demonstrado, A Peste (1947), na figura de Rieux, representa a resistência a um regime totalitarista que dizimou milhares de pessoas durante a Segunda Guerra Mundial. Como um literato, Riuex narra a fim de denunciar a dor, o medo instalado, a incerteza de um futuro, a perda da esperança e a solidão ocasionados pelo flagelo.

Como se sabe, os discursos metaficcionais historiográficos, na pósmodernidade, proporcionam uma transformação epistemológica, porque permitem uma evidenciação heterogênea: dos vencedores e dos vencidos. A história oficial, durante muito tempo, deificou aqueles e relegou estes, marginalizando-os e/ou limitando-os ao silenciamento e, até mesmo, ao apagamento total. Nesse sentido, narrativas como A Peste (1947) cumprem um papel social, ao assumir uma postura revisionista dos desígnios da história. A narrativa camusiana possibilita, assim, uma supressão das lacunas deixadas pela "historiografia tradicional, conservadora e preconceituosa, dando voz a tudo aquilo que foi negado, silenciado ou perseguido pela história" (ESTEVES, 1995, p. 29).

As justificativas de Dr. Rieux para a narração e materialização dos fatos ocorridos revelam o "testemunho do que tinha sido necessário realizar e que, sem dúvida, deveriam realizar ainda, contra o terror e sua arma infatigável" (CAMUS, 1947, p. 213). Assim, o romance traz um apelo para que esses males jamais sejam esquecidos, para que não se repitam, e para que não sejam chamados de "acontecimentos inesperados, imprevistos e imprevisíveis de 'acontecimentos fortuitos', ou 'de últimos suspiros do passado', condenando-os à irrelevância ou à famosa 'lata de lixo da história'” (ARENDT, 1985, p. 5).

Com base nisso, vale reafirmar que narrativas como A Peste (1947) são relevantes porque se ocupam de explicar a história dada como oficial sob múltiplos vieses, possibilitando, assim, novas leituras, percepções e construções de pensamentos críticos em relação ao que é imposto como verdadeiro. 
ARENDT, Hannah. Origens do totalitarismo. Tradução de Roberto Raposo. São Paulo: Companhia das letras, 2012.

ARENDT, Hannah. Da violência. Trad: Maria Claudia Drummond, 1985.

BERNARDO, Gustavo. 0 livro da metaficção. Rio de Janeiro: Tinta Negra Bazar Editorial, 2010.

CAMUS, Albert. A peste. Ed. Círculo do livro,1947.

COUTINHO, Afrânio. Notas de teoria literária. 2ed. Rio de Janeiro: Civilização Brasileira, 1978.

ESTEVES, A. R. 0 novo romance histórico brasileiro. In: ANTUNES, L. Z. (Org.) Estudos de literatura e lingüística. São Paulo: Arte \& Ciência, 1998. p.123-158.

ESTEVES, A. R. Lope de Aguirre: da história para a literatura. 1995. 220 f. Tese (Doutorado) - Universidade de São Paulo, São Paulo, 1995.

FELMAN, Shoshana. Educação e crise, ou as vicissitudes do ensino. In: Catástrofe e Representação: ensaios. NESTROVSKI, Arthur \& SELIGMANN-SILVA, Márcio (orgs.). São Paulo: Escuta, 2000.

HARTOG, François. Evidência da história: o que os historiadores veem. Tradução Guilherme João de Freitas Teixeira com a colaboração de Jaime A. Clasen, 1‥ ed., 1‥ reimp. Belo Horizonte: Autêntica Editora, 2013.

HOBSBAWN, Eric. Era dos extremos: o breve século XX (1914-1991). São Paulo: Companhia das Letras, 1995.

HUTCHEON, L. Poética do pós-modernismo - história, teoria, ficção. Tradução Ricardo Cruz. Rio de Janeiro: Imago, 1991.

JAKOBSON, R. Lingüística e comunicação. São Paulo: Cultrix, 1977.

LIMA, Luiz Costa. A Aguarrás do tempo: estudos sobre a narrativa. Rio de Janeiro: Ed. Rocco, 1989.

Pesavento, Sandra Jatahy. 0 mundo como texto: leituras da História e da Literatura. In Revista História da Educação, 2003. Disponível em: <https://www.seer.ufrgs.br/asphe/article/view/30220/pdf> . Acesso em: 21/12/2019. 
REIS, José Carlos. História e verdade: posições. In: Síntese - Revista de Filosofia, v. 27, no 89, 2000.SILVA, Haíde. A metaficção historiográfica no romance Os cus de Judas, de Antonio Lobo Antunes. Tese de doutorado. São Paulo, 2007.

WHITE, Hayden. Trópicos do discurso: ensaios sobre a crítica da cultura. Trad: Alípio Correia de França Neto. São Paulo: Editora da Universidade de São Paulo, 1994.

ZIZEK, S. Acontecimento: uma viagem filosófica através de um conceito. Tradução de Carlos Alberto Medeiros. Rio de Janeiro: Zahar, 2017.

\section{Para citar este artigo}

CARVALHO, K. da.S. A.; LOPES, M. S. de 0. A peste, de Albert Camus: uma leitura sob a ótica da metaficção historiográfica. Macabéa - Revista Eletrônica do Netlli, Crato, v. 9, n. 4, 2020, p. 468-482.

\section{As Autoras}

KEILIANE DA SILVA ARAÚJO CARVALHO é mestranda em Literatura pelo Programa de Pós-Graduação da Universidade Estadual do Piauí - UESPI - Graduada em Letras Português pela Universidade Estadual do Maranhão - UEMA.

MARIA SUELY DE OLIVEIRA LOPES é doutora em Teoria da Literatura pela Universidade Federal de Pernambuco (UFPE), Professora Adjunta da Universidade Estadual do Piauí (UESPI) atuando nas áreas de Teoria Literária, Crítica Literária, Literatura Brasileira. Atualmente é professora do Mestrado Profissional em Letras(PROFLETRAS) e do mestrado Acadêmico em Letras( UESPI). É membro do Grupo de Estudos Interdisciplinares em Literatura (INTERLIT) e filiada a ADHILAC. Possui Pós-Doutorado pela Universidade Federal do Piaui-UFPI. 